\title{
EVALUASI PENGENDALIAN INTERN SISTEM INFORMASI AKUNTANSI PENERIMAAN KAS ATAS PENJUALAN JASA KAMAR PADA BIG FISH HOTEL
}

\author{
Arif Rahman Modim ${ }^{1}$, Jantje J. Tinangon ${ }^{2}$, Sonny Pangerapan ${ }^{3}$ \\ ${ }^{1,2,3}$ Jurusan Akuntansi, Fakultas Ekonomi dan Bisnis, Universitas Sam Ratulangi, Jalan Kampus Bahu \\ Malalayang, Kota Manado, 95115, Indonesia \\ Email: modimarif@gmail.com
}

\begin{abstract}
Organizations to achieve sustainable position and possible opportunities requires efficient information systems. The purpose of the study is to evaluate the implementation an internal control in accounting information system cash receipt in Big Fish hotel (Piere Tendean Number. 107-108 Boulevard Manado). This research approach is qualitative descriptive with the type of case study research. Types of data used are primary data and secondary data. Data were collected through a preliminary survey, field research, observation, interviews, and documentation. The result show that accounting informations systems cash receipt at this hotel has been have well internal control. Although there were many problem has found, that there is no a job rotation to maintain employee independence in carrying out their duties, he absence of an internal supervisory unit that can guarantee security and finances, there is no surprising audit to check accurately.
\end{abstract}

Keywords : Accounting Information System, Cash Receipt, Internal Control

\section{PENDAHULUAN}

Pariwisata mempunyai peran penting dalam peningkatan ekonomi Indonesia saat ini. Banyak promosi yang dilakukan Kementerian Kebudayaan dan Pariwisata Indonesia baik di dalam maupun diluar negeri dalam mendukung programnya Wonderful of Indonesia yang ditargerkan dapat menaikan angka kunjungan wisatawan mancanegara ke Indonesia pada tahun 2019 yakni 20 juta wisatawan (www.kemenpar.go.id).

Semakin ketatnya persaingan usaha dan kebijakan Pemerintah Kota Manado yang sangat memprioritaskan sektor pariwisata dalam rangka menjadikan Kota Manado sebagai Kota Pariwisata Dunia menjadikan bisnis perhotelan berkembang pesat, di tengah persaingan bisnis yang begitu ketat serta semakin banyaknya para traveller dan backpacker anak muda yang melakukan travelling dengan low budget maka mereka mengincar hotel - hotel yang memasang tarif rendah, hal ini mengakibatkan menjamurnya bisnis hotel tarif rendah, dengan semakin ketatnya persaingan maka diperlukan suatu sistem yang efektif dan efisien dalam mendukung kelancaran operasional hotel, dengan biaya rendah maka diperlukan sebuah sistem yang menjaga sumber daya perusahaan dengan baik, karena sebuah kecurangan dan tidak teraturnya pencatatan dan siklus transaksi dapat mengakibatkan kemunduran bisnis ditengah persaingan serta bisnis terancam tutup.

Oleh karena itu, perlu adanya sebuah sistem informasi yang menjaga kelancaran bisnis dengan memberikan informasi akuntansi yang memadai sebagai masukan terhadap pihak pihak pemakai informasi dalam mengambil keputusan. Salah satu sistem informasi yang sangat diperlukan adalah sistem informasi akuntansi penerimaan kas. Adanya sistem informasi akuntansi kas yang baik akan dapat mendorong tercapainya transparansi dan akuntabilitas dan meminimalisir terjadinya kecurangan. Dengan adanya pengendalian intern dapat membantu perusahaan mencapai tujuan tersebut. Pengendalian intern memerlukan berbagai prosedur yang dirancang untuk melindungi penerimaan kas seperti adanya 
pemisahan tugas dan tanggung jawab dengan tepat, sehingga tidak ada karyawan yang merangkap jabatan. Selain jasa penginapan, hotel Big Fish menyediakan fasilitas lain seperti laundry \& dry cleaning, meeting room, restaurant, dan lain-lain. Namun yang menjadi sumber pendapatan utama adalah penerimaan dari jasa sewa kamar. Oleh karena itu, batasan penelitian yang diambil dalam penelitian ini adalah pengendalian intern sistem informasi akuntansi penerimaan kas dari sewa kamar. Adapun penelitian yang dilakukan meliputi proses sewa kamar dan sistem informasi penerimaan kas dari sewa kamar tersebut serta kesesuaian penerapan unsur pengendalian intern. oleh sebab itu, penulis tertarik melakukan penelitian tentang Pengendalian Intern Sistem Informasi Akuntansi Penerimaan Kas atas Penjualan Jasa Kamar pada Hotel Big Fish. Tujuan penelitian ini yaitu untuk mengetahui apakah penerapan sistem informasi akuntansi penerimaan kas dari sewa kamar Hotel Big Fish sudah sesuai dengan unsur unsur pengendalian intern sistem informasi akuntansi penerimaan kas?

\section{TINJAUAN PUSTAKA}

Menurut Susanto (2013:22) mengatakan sistem merupakan sarana dalam memberikan informasi kepada manajemen untuk mengetahui sumber daya perusahaan sehingga dapat mengambil keputusan dengan tepat. Sistem adalah kumpulan/group dari sub sistem/bagian/komponen apapun baik fisik ataupun non fisik yang saling berhubungan satu sama lain dan bekerja sama secara harmonis untuk mencapai satu tujuan tertentu Sistem informasi adalah serangkaian prosedur formal di mana data dikelompokkan, diproses menjadi informasi, dan didistribusikan kepada pemakai, Kadir (2014:9). Menurut O'Brien dan Marakas (2014) terdapat 3 dimensi kualitas informasi yaitu :

1. Dimensi Waktu yaitu informasi seharusnya disediakan ketika diperlukan, diperbaharui ketika disediakan, dan bisa disediakan tentang periode masa lalu, saat ini, dan masa depan.

2. Dimensi Konten yaitu informasi seharusnya bebas dari kesalahan, berkaitan dengan informasi yang diperlukan dari seorang penerima yang spesifik untuk sebuah situasi yang spesifik.

3. Dimensi Bentuk yaitu informasi harus disediakan dalam bentuk yang mudah dipahami,dalam sebuah urutan yang sudah ditentukan terlebih dahulu, bisa disajikan dalam bentuk naratif, numerik, grafik atau informasi, dan bisa disediakan dalam bentuk percetakan pada dokumen kertas, tampilan video atau media lainnya.

Menurut Krismiaji (2015:4) Sistem informasi akuntansi adalah sebuah sistem yang memproses data dan transaksi guna menghasilkan informasi yang bermanfaat untuk merencanakan, mengandalkan, dan mengoperasikan bisnis dan dapat menghasilkan informasi akuntansi harus melaksanakan tugas-tugas sebagai berikut:

1. Mengumpulkan transaksi data lain dan mengumpulkannya ke dalam sistem serta memproses data transaksi.

2. Menyimpan data untuk keperluan dengan memproduksi laporan, atau memungkinkan para pemakai untuk melihat sendiri data yang disimpan di komputer.

3. Menghasilkan informasi yang diperlukan dengan memproduksi laporan, atau memungkinkan para pemakai untuk melihat sendiri data yang disimpan di komputer.

4. Mengendalikan seluruh proses sedemikian rupa sehingga informasi yang dihasilkan akurat dan dapat dipercaya.

Sistem informasi akuntansi memiliki enam komponen menurut romney dan Steinbart (2015: 11) sebagai berikut :

1. Orang yang menggunakan sistem;

2. Prosedur dan instruksi yang digunakan untuk mengumpulkan, memproses dan menyimpan data; 
3. Data mengenai organisasi dan aktivitas-aktivitas bisnisnya;

4. Perangkat lunak yang digunakan untuk mengolah data;

5. Infrastruktur teknologi informasi, meliputi komputer, perangkat periferal, dan perangkat jaringan komunikasi yang digunakan dalam Sistem Informasi Akuntansi;

6. Pengendalian internal dan pengukuran keamanan yang menyimpan data.

Menurut Krismiaji (2015:213) Pengendalian (control) adalah proses mempengaruhi atau mengarahkan aktivitas sebuah objek, organisasi, atau sistem, Tujuan dilakukan pengendalian adalah untuk mencegah timbulnnya kerugian bagi sebuah organisasi, yang timbul antara lain karena sebab-sebab sebagai berikut.

1. Penggunaan sumber daya tidak efisien dan boros;

2. Keputusan manajemen yang tidak baik;

3. Kesalahan yang tidak sengaja dalam mencatat dan pemrosesan data;

4. Kehilangan atau kerusakan catatan secara tidak sengaja;

5. Kehilangan aktiva karena kecerobohan karyawan;

6. Tidak mentaati kebijakan manajemen dan peraturan lainnya oleh para karyawan;

7. Perubahan secara tidak sah terhadap sistem informasi akuntansi atau komponen komponen lainya.

Menurut Mulyadi (2016:129) Pengendalian intern merupakan bagian terpenting dalam perusahaan dimana pengendalian internal yang mengontrol seluruh aktivitas guna mencegah penyimpangan penyimpangan yang kemungkinan bisa terjadi dalam kegiatan oprasional perusahaan. Sistem pengendalian internal meliputi struktur organisasi, metode dan ukuranukuran yang dikoordinasikan untuk menjaga aset organisasi, mengecek ketelitian dan keandalan data akuntansi, mendorong efisiensi dipatuhinya kebijakan manajemen.

\section{METODE PENELITIAN}

Jenis Data. Data merupakan sekumpulan informasi yang diperlukan untuk pengambilan keputusan. Jenis data terbagi atas dua bagian yaitu :

1. Menurut Kuncoro (2013 : 145) Data Kualitatif adalah data yang bersumber dari lokasi penelitian yang berupa keterangan dan uraian untuk mengadakan analisis dan menyajikannya dalam penelitian melalui teori-teori yang berlaku.

2. Data Kuantitatif adalah data berbentuk angka-angka dan tabel-tabel kemudian melakukan uraian dan penafsiran dalam data-data tersebut Dalam penelitian ini digunakan data kualitatif mengenai Pengendalian Intern Sistem Informasi Akuntansi Penerimaan Kas atas Penjualan Jasa Sewa Kamar pada Hotel Big Fish.

Sumber Data. Sumber data yang digunakan dalam penelitian ini adalah data primer dan sekunder meliputi survey langsung, data umum mengenai sejarah dan latar belakang hotel, struktur organisasi, data khusus sesuai topik pembahasan untuk dianalisa seperti dokumen catatan serta beberapa literatur kepustakaan yang berkaitan dengan penelitian.

Teknik Pengumpulan Data. Teknik pengumpulan data yang digunakan dalam penelitian ini adalah sebagai berikut.

1. Dokumentasi. Melalui teknik dokumentasi ini penulis mengumpulkan dan mempelajari data yang dibutuhkan mengenai sejarah dan latar belakang hotel, struktur organisasi, serta menggunakan data sekunder yang merupakan data primer yang telah diolah lebih lanjut oleh pihak lain. Seperti bukti-bukti transaksi penerimaan yang dibuat hotel dan laporanlaporan yang sesuai dengan kebutuhan penulis.

2. Wawancara. Wawancara adalah dimana penulis dapat secara langsung menemui subjek untuk menggali informasi maupun melalui media tertentu seperti telepon atau chatting melalui internet. Penulis memilih teknik pengumpulan data dengan cara wawancara karena ingin mengetahui hal-hal dari responden secara lebih mendalam serta karena mempertimbangkan jumlah responden yang dituju lebih sedikit. 
Metode Analisis. Peneliti menggunakan metode analisis deskriptif dengan mengumpulkan data yang berhubungan dengan Pengendalian Intern Sistem Informasi Akuntansi Penerimaan Kas atas Penjualan Jasa Sewa Kamar pada Hotel Big Fish dan dibandingkan kesesuaiannya dengan teori unsur unsur pengendalian intern. Kemudian diadakan pembahasan masalah untuk menarik kesimpulan dan saran-saran sebagai bahan masukan bagi Manajemen Hotel Big Fish.

Teknik Analisis. Tahap-tahap yang dilakukan untuk mengevaluasi data adalah sebagai berikut :

1 Mempelajari penerapan Sistem Informasi Akuntansi Penerimaan Kas atas Penjualan Jasa Sewa Kamar pada Hotel Big Fish

2 Mengumpulkan data yang berkaitan dengan penelitian

3 Melakukan evaluasi Sistem Informasi Akuntansi Penerimaan Kas atas Penjualan Jasa Sewa Kamar pada Hotel Big Fish sesuai teori unsur - unsur pengendalian intern sistem informasi akuntansi penerimaan kas

4 Menarik kesimpulan dan memberikan saran berdasarkan evaluasi Sistem Informasi Akuntansi Penerimaan Kas atas Penjualan Jasa Sewa Kamar pada Hotel Big Fish

\section{HASIL PENELITIAN DAN PEMBAHASAN}

\subsection{Hasil Penelitian}

Analisis Unsur Unsur Pengendalian Intern Sistem Informasi Akuntansi Penerimaan Kas. Unsur-unsur pengendalian intern dalam sistem informasi akuntansi penerimaan kas yang menjadi dasar terhadap pembahasan pada Big Fish Hotel, yaitu :

1. Struktur organisasi yang memisahkan tanggung jawab fungsional secara tegas. Big Fish Hotel telah menempatkan para karyawan sesuai tugas pokok dalam menjalankan kegiatan perusahaan berdasarkan struktur organisasi yang tegas. Sehingga terdapat pembagian tugas yang jelas serta menghindari adanya rangkap tugas maupun satu transaksi yang dari awal sampai akhir transaksi hanya dikerjakan oleh satu orang.

2. Sistem wewenang dan prosedur pencatat yang memberikan perlindungan yang cukup terhadap kekayaan, utang, pendapatan dan biaya. Fungsi akuntansi mengeluarkan daftar piutang yang akan menjadi dasar penagihan oleh fungsi penagihan. Penyelewengan yang mungkin terjadi adalah kecurangan dalam melakukan penagihan dan pelaporan jumlah piutang dengan adanya kerja sama antara fungsi akuntansi dan fungsi penagihan. Sehingga harus adanya pihak lain yang bertugas dalam pemeriksaan dan pengawasan yang memiliki otorisasi yang kuat.

3. Praktik yang sehat dalam melaksanakan tugas dan fungsi setiap unit organisasi:

a. Setiap dokumen sudah mempunyai nomor urut cetak yang pemakaiannya dapat dipertanggungjawabkan oleh yang berwenang.

b. Pemeriksaan mendadak (suprised audit) yang mendorong karyawan melaksanakan tugasnya sesuai dengan aturan yang telah ditetapkan, tetapi Big Fish Hotel tidak menerapkan pemeriksaan mendadak (suprised audit).

c. Tidak adanya transaksi yang dari awal sampai akhir dikerjakan hanya dari satu unit organisasi.

Berikut Prosedur Sistem Informasi Akuntansi Penerimaan Kas melalui jasa sewa kamar :

a. Prosedur Penjualan. Receptionist melaporkan order penerimaan tamu ke bagian kasir secara online pada saat tamu check in. kasir menerima laporan order penerimaan tamu dari receptionist, kemudian mempersiapkan tiga lembar guest bill dan mengarsipkan sementara menurut kartu identitas tamu yang diberikan (KTP, SIM atau Passport).

b. Prosedur Penerimaan Kas. Pada saat tamu check out dan akan membayar, terlebih dahulu kasir melengkapi guest bill dengan tagihan-tagihan selama tamu menginap, setelah itu 
membuat cash receipt sebanyak tiga lembar. Cash receipt dan guest bill lembar I dimasukkan ke amplop dan diserahkan ke tamu sebagai bukti pembayaran yang sah. Kasir kemudian membuat summary front office cash receipt berdasarkan cash receipt dan guest bill. Kasir menyerahkan summary front office receipt, lembar ke II cash receipt dan guest bill ke general cashier beserta kas dari penerimaan sewa kamar selanjutnya kasir akan mengarsipkan lembar ke III cash receipt berdasar tanggal check out.

b. Perputaran jabatan (job rotation). Perputaran jabatan yang diadakan secara rutin dapat meningkatkan keahlian karyawan dan menghindari terjadinya persekongkolan di antara staf. Karena ketika terjadi perputaran jabatan, masingmasing karyawan dapat menilai kinerja karyawan sebelumnya yang menempati posisi tersebut dan dapat menemukan apabila terjadi kecurangan.

c. Pengambilan cuti bagi karyawan. Adanya cuti untuk setiap karyawan dan selama cuti, jabatan, karyawan yang bersangkutan akan digantikan untuk sementara oleh karyawan lain yang ditunjuk.

d. Secara periodik diadakan pencocokan fisik kekayaan dengan catatannya. Fungsi akuntansi akan mencatat hasil perhitungan kas pada buku kas bank, dan mencatat pembayaran piutang dalam kartu piutang serta langsung menginput ke dalam jurnal sebagai input data computer. setiap penerimaan tunai akan disetor seluruhnya ke bank pada hari yang sama. Selain itu, setiap hari dilakukan pencocokan fisik uang kas yang diterima dengan catatan akuntansi yang ada dalam sistem. Dan setiap bulan diadakan rekonsiliasi bank antara jurnal hasil inputan komputer dan data bank.

e. Pembentukan unit organisasi yang bertugas untuk mengecek efektifitas unsur-unsur sistem pengendalian yang lain. Tidak adanya unit yang bertugas sebagai pengawas atas dijalankannya sistem informasi akuntansi yang ditetapkan perusahaan

f. Karyawan yang mutunya sesuai dengan tanggung jawabnya. Manajemen Big Fish Hotel telah menggariskan tanggung jawab kepada karyawan secara tegas dan jelas. Pemantauan kas merupakan tugas dan tanggung jawab manajer keuangan dan setiap tahun diadakan pemeriksaan terhadap kas oleh auditor independen. 


\subsection{Pembahasan}

Tabel 1. Perbandingan antara Unsur-unsur Pengendalian internal menurut Mulyadi (2016:3) dengan Big Fish Hotel

\begin{tabular}{ccccc}
\hline No & $\begin{array}{c}\text { Menurut } \\
\text { Teori }\end{array}$ & $\begin{array}{c}\text { Hasil } \\
\text { Penelitian }\end{array}$ & $\begin{array}{c}\text { Berdasarkan } \\
\text { Hasil } \\
\text { Penilaian }\end{array}$ & Kesesuaian \\
\hline
\end{tabular}

A.Struktur Organisasi

1. Memisahkan antara Fungsi penagihan Terdapat pemisahan Sesuai

fungsi akuntansi, fungsi menagih berdasarkan pembagian tugas dan penagihan, dan fungsi daftar piutang yang tanggungjawab di Big penerimaan kas. dikeluarkan fungsi Fish Hotel pada masing akuntansi dan masing bagian.

penerimaan kas

dilakukan oleh kasir, semua penerimaan kas dari fungsi penagihan maupun kasir diterima dan dicatat oleh fungsi akuntansi

\section{B. Sistem Otorisasi Dan Pencatatan}

2. Fungsi penagihan Pada Big Fish Hotel melakukan penagihan fungsi penagihan hanya atas dasar daftar melakukan penagihan piutang yang harus piutang berdasarkan ditagih yang dibuat oleh daftar piutang yang fungsi akuntansi. dikeluarkan oleh fungsi

Dalam sistem Sesuai akuntansi.

\section{Praktik yang sehat}

3 Penggunaan

formulir Adanya no urut cetak bernomor urut tercetak di setiap dokumen yang pemakaiannya harus yang dipertanggung dapat dipertanggungjawabkan jawabkan oleh yang Penagihan oleh fungsi penagihan berdasarkan daftar piutang dari fungsi akuntansi, admin Big Fish Hotel memberikan jangka waktu 2 minggu untuk konsumen konsumen yang mau saja melunasi piutangnya. Proses pelunasannya bisa transfer melalui bank transfer atau visa. oleh yang berwenang berwenang

4 Pemeriksaan mendadak (suprised audit) Tidak adanya
pemeriksaan mendadak yang dilakukan oleh manajemen hotel

Adanya no urut cetak Sesuai di setiap dokumen sehingga bisa ditelusuri jika terdapat penyelewengan

(suprised audit)

Tidak adanya Tidak Sesuai

Pemeriksaan mendadak (suprised audit) menyebabkan manajemen tidak bisa menyelidiki apakah sisem dan prosedur akuntansi telah dilaksanakan secara baik 
Tabel 1. Perbandingan antara Unsur-unsur Pengendalian internal menurut Mulyadi (2016:3) dengan Big Fish Hotel

\begin{tabular}{|c|c|c|c|c|}
\hline No & $\begin{array}{c}\text { Menurut } \\
\text { Teori }\end{array}$ & $\begin{array}{c}\text { Hasil } \\
\text { Penelitian }\end{array}$ & $\begin{array}{c}\text { Berdasarkan } \\
\text { Hasil } \\
\text { Penilaian }\end{array}$ & Kesesuaian \\
\hline 5 & $\begin{array}{l}\text { Tidak ada transaksi } \\
\text { yang dilaksanakan dari } \\
\text { awal sampai akhir oleh } \\
\text { satu unit organisasi atau } \\
\text { satu orang, tanpa ada } \\
\text { campur tangan dari unit } \\
\text { organisasi lain atau } \\
\text { orang lain }\end{array}$ & $\begin{array}{l}\text { Setiap transaksi } \\
\text { penerimaan kas } \\
\text { melibatkan fungsi kasir } \\
\text { dan fungsi penagihan } \\
\text { sebagai penerima kas, } \\
\text { dan fungsi akuntansi } \\
\text { yang mencatat semua } \\
\text { penerimaan kas }\end{array}$ & $\begin{array}{l}\text { Adanya pemisahan } \\
\text { tanggung jawab dalam } \\
\text { suatu transaksi } \\
\text { sehingga tidak ada satu } \\
\text { unit yang mengerjakan } \\
\text { satu transaksi dari awal } \\
\text { hingga akhir }\end{array}$ & Sesuai \\
\hline 6 & $\begin{array}{l}\text { Adanya unit organisasi } \\
\text { independen yang } \\
\text { bertugas mengecek } \\
\text { efektifitas unsur-unsur } \\
\text { pengendalian intern }\end{array}$ & $\begin{array}{lr}\text { Tidak ada } & \text { unit yang } \\
\text { bertugas } & \text { untuk } \\
\text { mengecek } & \\
\text { dijalankannya } & \text { sistem } \\
\text { informasi } & \text { akuntansi } \\
\text { yang } & \text { ditetapkan } \\
\text { perusahaan } & \end{array}$ & $\begin{array}{l}\text { Tidak adanya satuan } \\
\text { pengawas intern dalam } \\
\text { perusahaan yang dapat } \\
\text { menjamin keamanan } \\
\text { kas dan keandalan } \\
\text { catatan akuntansi }\end{array}$ & Tidak Sesuai \\
\hline 7 & $\begin{array}{l}\text { Melakukan pencocokan } \\
\text { fisik kas yang ada di } \\
\text { tangan dengan jumlah } \\
\text { kas menurut catatan } \\
\text { akuntansi } \\
\text { periodik. }\end{array}$ & $\begin{array}{l}\text { Pencocokan fisik cash } \\
\text { on hand dengan } \\
\text { inputan sistem setiap } \\
\text { hari. Jumlahnya harus } \\
\text { sama dengan catatan } \\
\text { perusahaan. }\end{array}$ & $\begin{array}{l}\text { Pencocokan fisik cash } \\
\text { on hand dihitung dan } \\
\text { dilaporkan secara rinci } \\
\text { mengenai nilai-nya } \\
\text { sehingga bidang kasir } \\
\text { dan } \\
\text { catatan perusahaan } \\
\text { jumlahnya sama. }\end{array}$ & Sesuai \\
\hline 8 & $\begin{array}{lr}\begin{array}{l}\text { Perputaran } \\
\text { untuk }\end{array} & \text { jabatan } \\
\text { independensi } & \\
\text { pejabat } & \text { dalam } \\
\text { melakukan tugasnya. }\end{array}$ & $\begin{array}{l}\text { Pada Big Fish Hotel } \\
\text { tidak dilakukan } \\
\text { perputaran jabatan. }\end{array}$ & $\begin{array}{l}\text { Dalam Big Fish Hotel } \\
\text { belum } \\
\text { dilakukan perputaran } \\
\text { jabatan, karena jabatan } \\
\text { manager di Big Fish } \\
\text { Hotel berlaku tetap } \\
\text { dengan keterbatasan } \\
\text { pegawai dan } \\
\text { keterbatasan keahlian }\end{array}$ & Tidak sesuai \\
\hline 9 & $\begin{array}{l}\text { Pengambilan cuti bagi } \\
\text { karyawan yang berhak. }\end{array}$ & $\begin{array}{l}\text { Cuti karyawan pada } \\
\text { Big Fish Hotel diatur } \\
\text { oleh perusahaan } \\
\text { sehingga } \\
\text { meminimalisir } \\
\text { terjadinya human error } \\
\text { karena faktor kelelahan } \\
\text { dan meningkatkan } \\
\text { kinerja karyawan yang } \\
\text { baru bekerja setelah } \\
\text { cuti }\end{array}$ & $\begin{array}{l}\text { Big Fish Hotel } \\
\text { memberikan cuti } \\
\text { karyawan karena setiap } \\
\text { tenaga kerja berhak } \\
\text { memperoleh cuti dan } \\
\text { juga telah diatur dalam } \\
\text { undang-undang. }\end{array}$ & Sesuai \\
\hline 10 & $\begin{array}{l}\text { Hasil perhitungan kas } \\
\text { direkam dalam berita } \\
\text { acara } \\
\text { perhitungan kas dan } \\
\text { disetor ke bank pada } \\
\text { hari yang sama }\end{array}$ & $\begin{array}{l}\text { Adanya berita acara } \\
\text { perhitungan kas dan } \\
\text { uang tunai disetor } \\
\text { penuh ke bank pada } \\
\text { hari yang sama }\end{array}$ & $\begin{array}{l}\text { Hasil perhitungan kas } \\
\text { pada Big Fish Hotel } \\
\text { akan dicatat dalam } \\
\text { berita acara dan bagian } \\
\text { akuntansi rakan } \\
\text { menginput jurnal yang }\end{array}$ & Sesuai \\
\hline
\end{tabular}


Tabel 1. Perbandingan antara Unsur-unsur Pengendalian internal menurut Mulyadi (2016:3) dengan Big Fish Hotel

\begin{tabular}{|c|c|c|c|c|}
\hline No & $\begin{array}{c}\text { Menurut } \\
\text { Teori }\end{array}$ & $\begin{array}{c}\text { Hasil } \\
\text { Penelitian }\end{array}$ & $\begin{array}{c}\text { Berdasarkan } \\
\text { Hasil } \\
\text { Penilaian }\end{array}$ & Kesesuaian \\
\hline & & 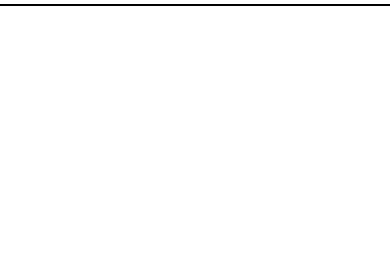 & $\begin{array}{l}\text { diperlukan sebagai } \\
\text { input data computer. } \\
\text { Dan uang tunai akan } \\
\text { langsung disetor ke } \\
\text { bank pada hari yang } \\
\text { sama. }\end{array}$ & \\
\hline \multicolumn{5}{|c|}{ D. Karyawan yang mutunya sesuai dengan tanggung jawabnya } \\
\hline 11 & $\begin{array}{c}\text { Karyawan yang } \\
\text { mutunya sesuai dengan } \\
\text { tanggung jawabnya }\end{array}$ & $\begin{array}{l}\text { Manajemen Big Fish } \\
\text { Hotel telah } \\
\text { menggariskan tanggung } \\
\text { jawab kepada masing- } \\
\text { masing personil secara } \\
\text { jelas. }\end{array}$ & $\begin{array}{c}\text { Pemantauan terhadap } \\
\text { kas menjadi tanggung } \\
\text { jawab manajer } \\
\text { keuangan. Setiap } \\
\text { karyawan selalu } \\
\text { dipantau berdasarkan } \\
\text { penilaian kinerja setiap } \\
\text { bulan dan setiap tahun } \\
\text { diadakan pemeriksaan } \\
\text { terhadap kas oleh } \\
\text { auditor independen. }\end{array}$ & Sesuai \\
\hline
\end{tabular}

Sumber : Hasil Data Olahan 2018

\section{KESIMPULAN DAN SARAN}

\subsection{Kesimpulan}

Kesimpulan dari penelitian ini adalah :

1. Unsur pengendalian intern struktur organisasi telah berjalan baik dimana adanya pemisahan pembagian tugas dan tanggung jawab pada masing-masing bagian.

2. Unsur pengendalian intern struktur organisasi sistem otorisasi dan pencatatan telah berjalan dengan baik dimana fungsi penagihan melakukan penagihan hanya atas dasar daftar piutang yang harus ditagih yang dibuat oleh bagian akuntansi.

3. Unsur pengendalian intern praktik yang sehat telah berjalan dengan baik dimana adanya no urut cetak di setiap dokumen sehingga bisa ditelusuri jika terdapat penyelewengan, tidak adanya ada transaksi yang dikerjakan oleh satu unit organisasi karena sudah ada pemisahan tanggung jawab dalam satu transaksi, dilakukannya Pencocokan fisik cash on hand setiap hari dibandingkan dengan catatan perusahaan, adanya pengaturan cuti karyawan, adanya berita acara perhitungan kas dan uang tunai langsung disetor penuh ke bank pada hari yang sama, Namun tidak adanya Pemeriksaan mendadak (suprised audit) menyebabkan manajemen tidak bisa menyelidiki apakah sisem dan prosedur akuntansi telah dilaksanakan secara baik serta tidak adanya satuan pengawas intern dalam perusahaan yang dapat menjamin keamanan kas dan kedalam catatan akuntansi dan belum dilakukannya perputaran jabatan karena keterbatasan pegawai dan keterbatasan keahlian.

4. Unsur pengendalian intern karyawan yang mutunya sesuai dengan tanggung jawabnya telah sesuai dimana manajemen Big Fish Hotel telah menggariskan tanggung jawab kepada masing-masing personil secara jelas.

\subsection{Saran}

Agar manajemen perusahaan dapat mempertahankan prosedur yang telah sesuai dan meningkatkan kualitas prosedur yang dianggap masih belum efektif dan efisien. 


\section{DAFTAR PUSTAKA}

Any, K. 2013. Analisis Sistem Informasi Akuntansi Penjualan dan Penerimaan Kas pada Penjualan Speedy PT Telkom Kandatel Malang. Jurnal Administrasi Bisnis Vol 01 No 01. Universitas Brawijaya. Malang

Azhar, S. 2013. Sistem Informasi Akuntansi Edisi Sembilan. Penerbit : Andi, Yogyakarta

Azize, E. 2016. The Impact of Accounting Information Systems on Firm Performance: Empirical Evidance in Turkish Small and Medium Sized Enterprises. International Review of Management and Marketing Vol 06 No 02. Turki

Bahari, I. S. 201). Analisis Sistem Akuntansi Penjualan dan Penerimaan Kas Dalam Upaya Peningkatan Pengendalian Intern pada PT. Sumber Purnama Sakti Motor Lamongan. Skripsi. Universitas Brawijaya. Malang

Budisatria, Y. 2010. Evaluasi Sistem Akuntansi Penerimaan Kas dari Sewa Kamar Hotel Baron Indah Surakarta. Skripsi. Universitas Sebelas Maret. Surakarta

Debby, H. 2016. Analisis Sistem Informasi Akuntansi Penerimaan Kas dari Penjualan Tunai Guna Meningkatkan Pengendalian Intern PT. Indomarco Prismatama. Skripsi. Universitas Bhayangkara Surabaya. Surabaya

Effendi, R. 2013. Accounting Principles "Prinsip - prinsip Akuntansi Berbasis SAK ETAP". Penerbit : PT. Rajagrafindo Persada

Empat, F. 2013. Analisis Sistem Informasi Akuntansi Penerimaan dan Pengeluaran Kas Pada Program Kemitraan dan Bina Lingkungan PT Bio Farma. Skripsi. Politeknik Negeri Bandung. Bandung

Fajar, S. 2015. Evaluasi Sistem Informasi Akuntansi Pendapatan dan Penerimaan Kas pada Swiss-Belinn Hotel Malang. Skripsi. Universitas Kanjuruhan. Malang

Hery. 2014. Pengendalian Akuntansi dan Manajemen. Penerbit: Kencana, Jakarta

Ikatan Akuntan Indonesia. 2017. Pernyataan Standar Akuntansi Keuangan PSAK No 2. Penerbit: Salemba Empat, Jakarta

Kadir, A. 2014. Pengenalan Sistem Informasi. Penerbit : Andi, Yogyakarta

Krismiaji. 2015. Sistem Informasi Akuntansi Edisi Keempat. UPP STIM YKPN, Yogyakarta

Kuncoro. 2013. Metode Riset Untuk Bisnis dan Ekonomi. Penerbit : Erlangga, Jakarta

Maknunah, J. (2015). Analisis Sistem Informasi Akuntansi Penerimaan dan Pengeluaran Kas Pada Lembaga Pendidikan. SMATIKA Jurnal Vol 05 No 02. Sekolah Tinggi Informatika dan Komputer Indonesi. Malang

Mulyadi. 2016. SistemAkuntansi. Penerbit: Salemba Empat, Jakarta

Muhammad, I. F. 2015. Analisa Sistem Informasi Akuntansi Penerimaan dan Pengeluaran Kas Guna Mendukung Pengendalian Intern Perusahaan Pada PT Tambora Mulyorejo Malang. Universitas Bhayangkara. Surabaya

Mukjizatiah, S. 2016 Analisis Sistem Informasi Akuntansi Penerimaan dan Pengeluaran Kas Pada PT Mardiatama Konstruksi Palembang. STIE Multi Data. Palembang

Ni Wayan Esteria, Harijanto Sabiono, Linda Lambey. 2016. Analisis Sistem Akuntansi Penerimaan dan Pengeluaran Kas Pada PT Hasjrat Abadi Manado. Jurnal Berkala Ilmiah Efisiensi Vol 16 No 04. Universitas Sam Ratulangi. Manado

O’Brien dan Marakas. 2014. Sistem Informasi Manajemen, Penerbit : Salemba Empat, Jakarta

Permana, T. A. 2017. Analisis Penerapan Sistem Informasi Akuntansi Penerimaan Kas pada Klinik Adhiwarga PKBI DIY. Skripsi. Universitas Sanata Dharma. Yogyakarta

Romney, Marshall B, dan Steinbart. 2015. Sistem Informasi Akuntansi Edisi 13 alihbahasa : Kikin Sakinah, Nur Safira, dan Novita Puspasari. Penerbit : Salemba Empat, Jakarta

Rr. Fanny Villiant Arisqua, Isharijadi, Anggita Langgeng Wijaya. 2017. Analisis Sistem Informasi Akuntansi Penerimaan dan Pengeluaran Kas Guna Efektifitas 
Pengendalian Intern pada PDAM Tirta Dharma Purabaya Kabupaten Madiun. Journal Vol 05 No 01. Forum Ilmiah Pendidikan Akuntansi - Universitas PGRI Madiun. Madiun

Rahardian. 2016. Analisis Sistem Informasi Akuntansi Penerimaan Kas Jasa Dengan Metode DAD Pada PT Metropest Control. Skripsi. Universitas Gunadarma. Jakarta

Sahawneh, Nizar. 2016. Evaluation of Accounting Information System in Meeting the Requirements of Financial and Managerial Performance " Field Study in The United Arab Emirates Private Hospitals. International Journal of Humanities and Socal Science Vol 06 No 04. University in the Emirates

Saifudin. 2017. Analisis Sistem Informasi Akuntansi Penerimaan dan Pengeluaran Kas Dalam Meningkatkan Pengendalian Internal atas Pendapatan pada RSUP Dr. Kariadi Semarang. Skripsi. Universitas Semarang. Semarang

Sujarweni, V. W. 2015. Sistem Akuntansi. Penerbit : Pustaka Baru Press, Yogyakarta

Susanto. 2013. Sistem Informasi Manajemen. Penerbit : Lingga Jaya, Jakarta

Samryn, L. M. 2015. Pengantar Akuntansi. Penerbit : PT Rajagrafindo, Jakarta

Susan, P. T. 2017. A Review of the Impact of Accounting Information System for Effective Internal Control on Firm Performance on Nigerian Stock Exchange. Indian Journal of Finance ad Banking Vol 01 No 02. Taraba State University. Nigeria

Tunggal, A. 2013. Pokok - pokok COSO Based Auditing. Penerbit : Harvarindo, Jakarta 